\title{
Chemical composition of gallstones resistant to dissolution therapy with chenodeoxycholic acid
}

\author{
M J WHITING,* V JARVINEN, AND J McK WATTS \\ From the Department of Surgery, Flinders Medical Centre, Flinders University of South Australia, \\ South Australia
}

SUMMARY The gallstones of 14 patients, who had been treated unsuccessfully with chenodeoxycholic acid (15 mg/kg/day) for at least six months, were obtained at cholecystectomy. The stones were then analysed for their cholesterol and calcium content. Two patients' stones were black in colour and low in cholesterol content, and were classified as pigment stones. Of the remaining 12 patients' stones, which all contained more than $70 \%$ cholesterol, 10 contained at least $1 \%$ calcium on the stone surface. In two patients, the surface contained sufficient calcium to form a radioopaque layer, although the stones had been radiolucent at the start of dissolution therapy. Overall, the results suggest that deposition of calcium salts inhibits the dissolution treatment of gallstones with chenodeoxycholic acid, irrespective of the radiolucency of the stones.

Several clinical trials of the efficacy of chenodeoxycholic acid (CDCA) in dissolving radiolucent gallstones in functioning gallbladders have indicated that stones decrease in size during treatment in about one-half of patients, while in only one-third of patients do stones completely dissolve. ${ }^{1-5} \dot{A}$ number of reasons have been proposed to explain why the gallstones of some patients dissolve while others do nut. Many of these reasons relate to the properties of the stones chemselves, such as stone size or mass, cholesterot content, and the presence or absence of a calcified rim. Indeed, in vitro studies with animal bile have shown that these properties are important in determining the rate of human gallstone dissolution ${ }^{67}$ and clinical studies have demonstrated that patients with radio-opaque stones, and a high calcium salt concentration, rarely respond to chenodeoxycholic acid treatment. ${ }^{8}{ }^{9}$

Patients with gallstones who have been treated unsuccessfully with CDCA may subsequently be referred for cholecystectomy, either electively or if acute symptoms develop. The gallstones from these patients are then available for analysis to determine if unusual chemical features are present which may have influenced the outcome of dissolution treatment. In this report, we describe the chemical

*Address for corruspondence: Dr M Whiting, Department of Surgery, Flinders Medical Centre, Bedford Park, South Australia, 5042.

Received for publication 5 August 1980 composition of gallbladder stones collected at operation from 14 patients who had been treated unsuccessfully with CDCA for at least six months. In addition, the calcium content of these stones is compared with that of a group of radiolucent cholesterol stones collected from 89 patients who had functioning gallbladders and were not treated with CDCA.

\section{Methods}

COLLECTION OF GALLSTONES

Gallstones were obtained at cholecystectomy from 14 patients (eight men and six women; age range 27 to 74 years). All patients had been previously treated for radiolucent stones less than $2 \mathrm{~cm}$ diameter in a functioning gallbladder with either CDCA alone (eight patients; $15 \mathrm{mg} / \mathrm{kg} /$ day; Weddel Pharmaceuticals, London), or in combination with soya bean phospholipid (six patients; $2 \cdot 25 \mathrm{~g} /$ day; Nattermann, Cologne), for at least six months. The efficacy of the combination treatment to dissolve gallstones is not less than CDCA alone (Watts, Down, and Bradley, unpublished results). No reduction in gallstone size was seen in any patient at oral cholecystography performed at six monthly intervals. Twelve of the patients presented for elective cholecystectomy, while two presented with acute symptoms. The median time between 
ceasing dissolution treatment and operation was 2.5 months (range one to 16 months).

Gallstones were removed from the gallbladder, washed free of bile with methanol and distilled water, and dried. After weighing, a thin $(<1 \mathrm{~mm})$ surface layer was sectioned from the stones from each patient and a sample from the stone centre was also taken for cholesterol and calcium determination. Total stone cholesterol and calcium was determined after grinding several stones, or half a stone when only one was present, to a fine powder with a mortar and pestle.

Gallstones were also obtained from 89 consecutive patients (24 men and 65 women; age range 20 to 74 years) presenting for cholecystectomy with radiolucent cholesterol stones in a functioning gallbladder. These patients were not treated with CDCA, and their stones were analysed for total cholesterol and calcium, and for surface and interior calcium in a random sample of 20 stones.

\section{CHEMICAL ANALYSIS OF GALLSTONES Cholesterol}

Samples of gallstone powder (approximately 50 $\mathrm{mg}$ ) were dried at $60^{\circ} \mathrm{C}$ overnight to achieve constant weight, and were then extracted twice with $4 \mathrm{ml}$ isopropanol at $60^{\circ}$ for one hour. The isopropanol extracts were combined, made up to $10 \mathrm{ml}$ final volume, and cholesterol was estimated by gas-liquid chomatography, using cholesterol isopropyl ether as internal standard. The column $(1.2 \mathrm{~m} \times 2 \mathrm{~mm}$ i.d.) used for cholesterol determination was packed with $3 \%$ SP-2250 on Supelcoport 100-120 mesh (Supelco, Inc., Bellafonte, Penn., USA) and used at $265^{\circ}$ with nitrogen $(30 \mathrm{ml} / \mathrm{min})$ as carrier gas.

\section{Calcium}

The residue remaining after solvent extraction was treated with $2 \mathrm{ml}$ of $1 \mathrm{M}$ nitric acid, centrifuged and the supernatant collected. Concentrated nitric acid $(0.2 \mathrm{ml})$ was added to the residue, followed by $1 \mathrm{ml}$ of water, and the centrifugation was repeated. After washing the pellet with water, the combined supernatants were made up to $10 \mathrm{ml}$ with water, and calcium estimated on a Varian Techtron AA6 atomic absorption spectrophotometer.

\section{ANALYSIS OF BILIARY LIPIDS}

Bile collected by duodenal intubation was analysed for cholesterol, bile acids, and phospholipid as follows. Within one hour of collection, duplicate $50 \mu \mathrm{l}$ aliquots of bile were mixed with $50 \mu \mathrm{l}$ cholesterol isopropyl ether $(5 \mathrm{mM})$ as internal standard and then subjected to solvent extraction by the
Folch procedure. ${ }^{10}$ Aliquots of the lower phase were taken and evaporated to dryness for phospholipid estimation $^{11}$ and for cholesterol determination by gas-liquid chromatography, using the same conditions as described for gallstone cholesterol estimation. Total bile acids were determined enzymatically' ${ }^{12}$ after dilution of bile with $70 \%$ (v/v) methanol.

The cholesterol saturation index was calculated by the method of Thomas and Hofmann ${ }^{13}$ using the cholesterol equilibrium saturation limit of Holzbach et al. ${ }^{14}$

\section{STATISTICS}

The statistical test used was the non-parametric Mann-Whitney U test.

\section{Results}

COMPLIANCE WITH CDCA TREATMENT

During dissolution treatment with CDCA, compliance was assessed in six patients by bile lipid analysis. The biliary cholesterol saturation index was reduced after three months CDCA treatment from $1 \cdot 19 \pm 0 \cdot 28$ to $\mathbf{0} \cdot 80 \pm 0 \cdot 24$ (mean \pm SD) with all bile samptes analysed except one becoming unsaturated with respect to.cholesterol. The percentage CDCA in bile changed from $41 \pm 9$ to $88 \pm 6 \%$. In another five patients, compliance was assessed by serum bile acid analysis ${ }^{15}$ and the predicted percent CDCA in bile changed after treatment from $49 \pm 7 \%$ to $83 \pm 4 \%$.

\section{DESCRIPTION OF GALLSTONES RESISTANT TO DISSOLUTION TREATMENT}

Details of patients and the properties of their gallstones which were resistant to dissolution treatment are shown in Table 1. Many of the patients were obese, as determined by their body mass index (weight in $\mathrm{kg} /(\text { height in } \mathrm{m})^{2}$ ), for which the normal range is $20-25 .{ }^{16}$ The average time of treatment with CDCA was 10 months, with all patients receiving at least six months' treatment. There was a wide variation in the number of stones found in each patient's gallbladder, ranging from a single stone to approximately 200 small stones. Half the patients had rounded stones, which were usually solitary while the rest were multiple and faceted. The range of stone sizes present in each patient frequently included stones with a diameter over $10 \mathrm{~mm}$ and the total mass of stones varied from 0.3 to $34.3 \mathrm{~g}$.

Three patients' stones were black in colour (nos. 6,7 , and 14) suggesting that they were pigment stones. Chemical analysis confirmed that two of these stones (nos. 6 and 7) were low in cholesterol content compared with the others, all of which contained at least $70 \%$ cholesterol. The black stones 
Table 1 Details of patients and properties of gall bladder stones collected at cholecystectomy from 14 patients who failed dissolution treatment with chenodeoxycholic acid

\begin{tabular}{|c|c|c|c|c|c|c|c|c|c|}
\hline Patient no. & $\begin{array}{l}\text { Sex and age } \\
(y r)\end{array}$ & $\begin{array}{l}\text { Body mass } \\
\text { index }\end{array}$ & $\begin{array}{l}\text { Duration of } \\
\text { treatment } \\
\text { (months) }\end{array}$ & $\begin{array}{l}\text { Number of } \\
\text { stones }\end{array}$ & Shape $\ddagger$ & $\begin{array}{c}\text { Mass } \\
(\mathrm{g})\end{array}$ & $\begin{array}{l}\text { Diameter } \\
\text { range } \\
(\mathrm{mm})\end{array}$ & $\begin{array}{l}\text { Cholesterol } \\
\text { content } \\
(\%)\end{array}$ & $\begin{array}{l}\text { Calcium } \\
\text { content } \\
(\%)\end{array}$ \\
\hline $\begin{array}{r}1 \\
2 \\
3 \\
4 \\
5 \\
6 \\
7 \\
8 \\
9 \\
10 \\
11 \\
12 \\
13 \\
14\end{array}$ & $\begin{array}{l}\text { M } 53 \\
\text { F } 53 \\
\text { F } 58 \\
\text { F } 35 \\
\text { F } 27 \\
\text { M } 52 \\
\text { F } 74 \\
\text { M } 50 \\
\text { M } 54 \\
\text { M } 41 \\
\text { F } 72 \\
\text { M } 56 \\
\text { M } 45 \\
\text { M } 57\end{array}$ & $\begin{array}{l}28 \cdot 7 \\
32 \cdot 8 \\
21 \cdot 1 \\
37 \cdot 6 \\
32 \cdot 3 \\
27 \cdot 4 \\
24 \cdot 6 \\
34 \cdot 4 \\
22 \cdot 6 \\
29 \cdot 8 \\
32 \cdot 0 \\
26 \cdot 0 \\
26 \cdot 6 \\
21 \cdot 7\end{array}$ & $\begin{array}{r}8 \\
6 \\
6 \\
6 \\
12 \\
18 \\
12 \\
12 \\
12 \\
6 \\
12 \\
14 \\
12 \\
14 \\
6\end{array}$ & $\begin{array}{r}70 \\
60 \\
37 \\
14 \\
9 \\
1 \\
\sim 200 \\
1 \\
5 \\
1 \\
7 \\
1 \\
1 \\
5\end{array}$ & $\begin{array}{l}\mathbf{F} \\
\mathbf{F} \\
\mathbf{F} \\
\mathbf{F} \\
\mathbf{R} \\
\mathbf{R} \\
\mathbf{R} \\
\mathbf{R} \\
\mathbf{F}, \mathbf{R} \\
\mathbf{R} \\
\mathbf{F} \\
\mathbf{R} \\
\mathbf{R} \\
\mathbf{F}\end{array}$ & $\begin{array}{r}6 \cdot 1 \\
34 \cdot 3 \\
7 \cdot 5 \\
8 \cdot 0 \\
0 \cdot 4 \\
0 \cdot 3 \\
5 \cdot 7 \\
4 \cdot 3 \\
5 \cdot 6 \\
3 \cdot 7 \\
1 \cdot 1 \\
1.0 \\
1 \cdot 3 \\
1.6\end{array}$ & $\begin{array}{c}2-14 \\
6-22 \\
7-16 \\
10-12 \\
2-10 \\
15 \\
1-5 \\
20 \\
4-17 \\
24 \\
6-7 \\
12 \\
12 \\
5-12\end{array}$ & $\begin{array}{r}91 \\
98 \\
96 \\
93 \\
83 \\
1 \\
47 \\
99 \\
99 \\
94 \\
83 \\
84 \\
71 \\
91 \\
91\end{array}$ & \begin{tabular}{l|}
0.8 \\
1.0 \\
0.5 \\
1.2 \\
1.1 \\
1.6 \\
7.7 \\
0.2 \\
0.7 \\
3.8 \\
2.4 \\
8.8 \\
1.3 \\
0.9
\end{tabular} \\
\hline
\end{tabular}

*Weight (kg)/height ${ }^{2}$ (metres)

†Patients 1-8 were treated with chenodeoxycholic acid alone $(15 \mathrm{mg} / \mathrm{kg} / \mathrm{day})$, while patients 9-14 were treated with chenodeoxycholic acid plus phospholipid ( $2 \cdot 25 \mathrm{~g} /$ day $)$.

†F: faceted, $\mathbf{R}$ : rounded.

of patient no. 14 were predominantly cholesterol, but were coated with a thin layer of dark pigment. All stones contained calcium with a range of values from $0.2 \%$ to $8.8 \%$.

\section{DISTRIBUTION OF CHOLESTEROL AND}

\section{CALCIUM WITHIN THE GALLSTONES}

In addition to determining the total cholesterol and calcium content of the gallstones, the distribution of cholesterol and calcium throughout the stones was examined by separate analysis of samples taken from the surface and interior of the stones. The results are shown in Table 2 . In the cholesterol stones, a common finding was a higher concentration of calcium in the surface layer of the stones compared with the interior. This was the case in 11 of the 12 cholesterol stones, with the ratio of exterior to interior calcium reaching values as high as 21 (median ratio $7 \cdot 8$ ). Ten of the 12 cholesterol stones had at least $1 \%$ calcium in the stone surface. A high calcium content in the surface was always accompanied by a lower surface cholesterol content relative to the interior of the stone.

In two of the patients with solitary cholesterol stones (nos. 10 and 12), a radio-opaque rim developed on the stones during dissolution treatment. The calcium content of the surface in these two cases was $9 \cdot 2$ and $8 \cdot 4 \%$. Trotman et al. ${ }^{17}$ have previously shown that a calcium concentration of more than $4 \%$ usually results in radio-opacity of gallstones on radiographic examination. The calcium salt present on the surface of these stones is likely to be calcium carbonate, as bubbles of gas (presumably carbon dioxide) were released from fragments of stone

Table 2 Comparison of cholesterol and calcium content of surface and interior of gallbladder stones collected at cholecystectomy from 14 patients who failed dissolution treatment with CDCA

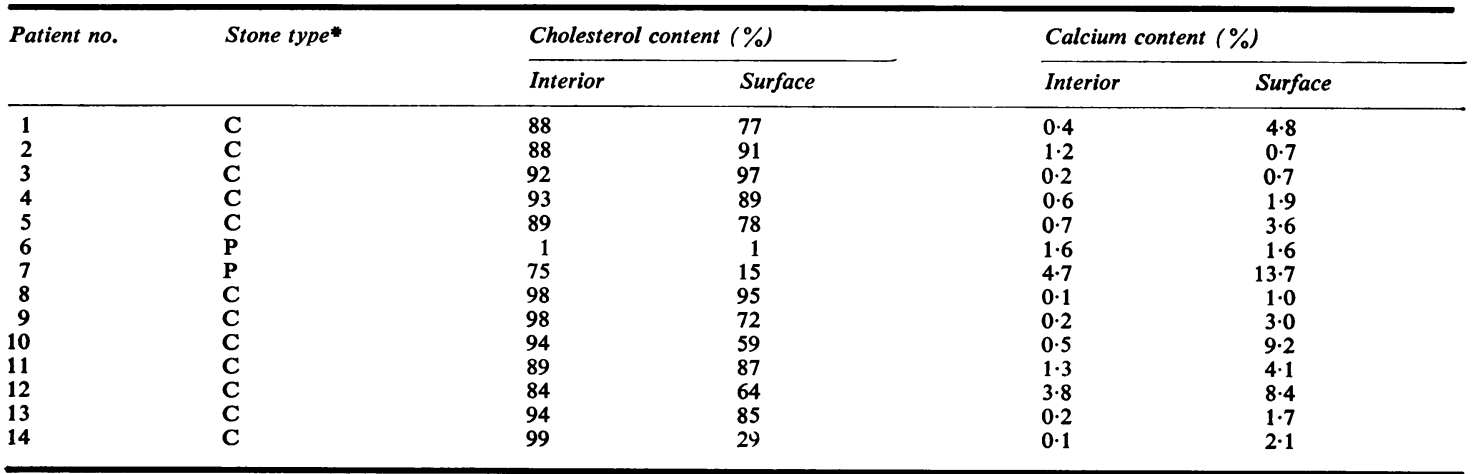

C: cholesterol (total cholesterol content $>50 \%$ ).

P: pigment (total cholesterol content $<50 \%$ ). 
surface, but not the interior, when immersed in $1 \mathrm{M}$ nitric acid.

CALCIUM CONTENT AND DISTRIBUTION IN RADIOLUCENT CHOLESTEROL GALLSTONES NOT TREATED WITH CDCA

To determine the amount of calcium present in cholesterol gallstones from patients who were not treated with CDCA, radiolucent stones containing more than $70 \%$ cholesterol were collected from 89 patients presenting for cholecystectomy with a functioning gallbladder. These stones were then analysed for calcium, and a range of values from 0 to $4.1 \%$ was found with the median value being $0.3 \%$. This was significantly lower $(P=0.01)$ than the amount of calcium present in the cholesterol stones resistant to dissolution treatment with CDCA (median $1.0 \%$, range 0.5 to $8.8 \%$, see Table 1 ).

The interiors and surface layers of stones collected from 20 patients sampled randomly from the 89 patients not treated with CDCA were then analysed to determine the distribution of calcium throughout the stones. In 13 of these stones, the surface contained a higher concentration of calcium than the interior, while, in six stones, the reverse was true. In one patient's stones, there was no difference between the surface and the interior of the stone. The median ratio of surface to interior calcium content in this group was $2 \cdot 4$, which was significantly lower $(\mathrm{P}<0.01)$ than the value of 7.8 for the stones which were unaffected by dissolution treatment.

\section{Discussion}

A summary of recent results of clinical trials from five different groups investigating the efficacy of CDCA in dissolving gallstones indicates that only 70 out of 215 patients $(33 \%)$ completely dissolved their stones, while 46 out of $215(21 \%)$ showed evidence of partial dissolution. ${ }^{1-5}$ The reasons why some patients do not dissolve their stones are not completely clear, but several factors have been identified as being important in determining the outcome of dissolution treatment.

One of these factors is the dosage of CDCA, which must be adequate to produce unsaturated bile in all patients. It has been accepted by most groups that $15 \mathrm{mg} / \mathrm{kg} /$ day is the optimum dose. ${ }^{4}$ Other factors are patient compliance and the length of treatment. At least six months are required to allow the slow process of dissolution to occur. ${ }^{4}$ In addition, the gallbladder should have good function-that is, opacify well during cholecystography and contract promptly in response to a meal, so that stones are continually exposed to unsaturated bile secreted by the liver. There is also some evidence that grossly obese patients will not respond to CDCA treatment ${ }^{4}$ because excessive cholesterol secretion prevents the bile from becoming unsaturated. ${ }^{18}$

The 14 patients reported in this study were all treated with CDCA at $15 \mathrm{mg} / \mathrm{kg} /$ day for at least six months, complied with treatment in the 11 cases examined, and had functioning gallbladders. While many of the patients were obese (median body mass index $28 \cdot 0$; range $21 \cdot 1-37 \cdot 6$ ), they were not significantly more obese than a group of 10 patients (median body mass index $26 \cdot 3$, range 18.3-32.7) whose stones were completely dissolved after CDCA treatment (unpublished results). Failure to show any response to CDCA treatment therefore must involve other factors. One such factor of great importance is the size and chemical composition of the stones themselves.

As expected from the mechanisms of action of CDCA, early studies indicated that radio-opaque stones which are low in cholesterol content (pigment stones) are not suitable for dissolution therapy. ${ }^{89}$ On the other hand, a potential error exists in assuming that all radiolucent stones are rich in cholesterol. This error has been estimated to be between 14 and $20 \%$ by other workers ${ }^{17}{ }^{19}$ and must account for some treatment failures.

Of the 14 patients who failed dissolution treatment and whose stones were analysed in this study, only two could be classified as having low cholesterol or pigment stones. One patient had a large (diameter $1.5 \mathrm{~cm}$ ) solitary non-cholesterol stone of low calcium content. This type of stone is rare, as pigment stones are usually less than $1 \mathrm{~cm}$ diameter and multiple. ${ }^{20}$ A second case of low cholesterol stones was found, where approximately 200 small stones had a predominantly cholesterol central core which was coated with a layer of black, calcium-containing pigment.

A feature of the remaining 12 patients' stones, which all contained $70 \%$ or more cholesterol, was the higher calcium content compared with radiolucent cholesterol stones collected from patients not treated with CDCA. In addition, there was a markedly uneven distribution of calcium between the surface and the interior of the stones, with 11 of the patients having a greater calcium concentration on the surface. In fact, in two patients, the calcium layer in the stone surface reached sufficient concentration to become radio-opaque, although the stones were lucent at the start of CDCA therapy. As eight other patients had surface calcium levels which were over $1 \%$, it is possible that a layer of calcium salt, probably calcium carbonate in most cases, formed a barrier between the cholesterol in the stone and the solubilising bile in the gallbladder. Almost all gallstones contain some calcium salts 
and these are rarely distributed uniformly throughout the stone but are concentrated in layers, often on the stone surface. A layer on the outside of the stone could completely prevent dissolution, while a layer within the stone could allow partial dissolution of the stone until the layer is reached. The presence of calcium carbonate on the surface of gallstones has been described previously and may be associated with a raised total $\mathrm{CO}_{2}$ concentration in common bile duct bile ${ }^{21}$ rather than a change in biliary calcium concentration. ${ }^{22}$

Other factors, such as stone size and number of stones, are likely to affect the rate of dissolution, and treatment periods in excess of 12 months may be required to effect a detectable reduction in gallstone size in some patients. However, it appears from these results that the presence of calcium carbonate in gallstones inhibits dissolution, even though the amount and distribution of calcium within the stone may not result in it being radio opaque. Gallstones from patients over 50 years old contain significantly more calcium than stones from patients less than $50^{19}$ and this finding is consistent with the deposition of calcium salts on the surface of old ( $>$ six years) gallstones, as suggested by Wolpers. ${ }^{23}$ CDCA therapy should therefore be most effective in young patients with cholesterol gallstones which are recent in origin and contain low levels of calcium salts.

We wish to thank the surgical staff of our department for collecting the gallstones and other samples. Chenodeoxycholic acid was supplied by Weddel Pharmaceuticals, London, and essential phospholipid (EPL) by Nattermann $\mathrm{GmbH}$, Cologne.

\section{References}

${ }^{1}$ Barbara L, Roda E, Roda A, Sama C, Festi D, Mazella GL, Aldini R. The medical treatment of cholesterol gallstones: experience with chenodeoxycholic acid. Digestion 1976; 14: 209-19.

${ }^{2}$ Bateson MC, Ross PE, Murison J, Bouchier IAD. Comparison of fixed doses of chenodeoxycholic acid for gallstone dissolution. Lancet $1978 ; 1$ : 1111-4.

${ }^{3}$ Beker S. Treatment of cholesterol gallstones with chenic acid. Am J Gastroenterol 1977; 68: 456-60.

'Dowling RH. Chenodeoxycholic acid therapy of gallstones. Clin Gastroenterology 1977; 6: 141-63.
${ }^{5}$ Thistle JL, Hofmann AF, Otto BJ, Stephens DH. Chenotherapy for gallstone dissolution. I. Efficacy and safety. JAMA 1978; 239: 1041-6.

${ }^{16}$ Bell GD, Sutor DJ, Whitney B, Dowling RH. Factors influencing human gallstone dissolution in monkey, dog and human bile. Gut 1972; 13: 836 (abstract).

${ }^{7}$ Bell GD. The dissolution of gallstones. Top Gastroenterol 1975; 2: 237-54.

${ }^{8}$ Thistle JL, Hofmann AF. Efficacy and specificity of chenodeoxycholic acid therapy for dissolving gallstones. N Engl J Med 1973; 289: 655-9.

${ }^{9}$ Iser JH, Dowling RH, Mok HYI, Bell GD. Chenodeoxycholic acid treatment of gallstones. $N$ Engl J Med 1975; 293: 378-83.

${ }^{10}$ Folch J, Lees M, Sloane-Stanley GH. A simple method for the isolation and purification of total lipids from animal tissue. J Biol Chem 1957; 226: 497-509.

${ }^{11}$ Bartlett GR. Phosphorus assay in column chromatography. J Biol Chem 1959; 234: 466-8.

${ }^{12}$ Palmer RH. The enzymatic assay of bile acids and related 3 $\alpha$-hydroxysteroids. Meth Enzymol 1969; 15: 280-8.

${ }^{13}$ Thomas P, Hofmann AF. A simple calculation of the lithogenic index of bile. Gastroenterology 1973; 65: 697-700.

${ }^{14}$ Holzbach RT, Marsh M, Olszewski M, Holan K. Cholesterol solubility in bile. Evidence that supersaturated bile is frequent in healthy man. $J$ Clin Invest 1973; 52: 1467-79.

${ }^{15}$ Whiting MJ, Watts JMcK. Prediction of the bile acid composition of bile from serum bile acid analysis during gallstone dissolution therapy. Gastroenterology 1980; 78: $220-5$.

${ }^{16}$ Florey $\mathrm{C} \mathrm{du} \mathrm{V}$. The use and interpretation of ponderal index and other weight-height ratios in epidemiological studies. J Chronic Dis 1970; 23: 93-103.

${ }^{17}$ Trotman BW, Petrella E, Soloway RD, Sanchez H, Morris T and Miller WT. Evaluation of radiographic lucency or opaqueness of gallstones as a means of identifying cholesterol or pigment stones. Gastroenterology 1975; 68: 1563-6.

${ }^{18}$ Shaffer EA, Small DM. Biliary lipid secretion in cholesterol gallstone disease. J Clin Invest 1977; 59: $828-40$.

${ }^{19}$ Bell GD, Dowling RH, Whitney B, Sutor DH. The value of radiology in predicting gallstone type when selecting patients for medical treatment. Gut 1975; 16: 359-64.

${ }^{20}$ Soloway RD, Trotman BW, Ostrow JD. Pigment gallstones. Gastroenterology 1977; 72: 167-82.

${ }^{21}$ Sutor DJ, Wilkie LI. Calcium carbonate in human gallstones and total $\mathrm{CO}_{2}$ in bile. Gut 1978; 19: 220-4.

${ }^{22}$ Sutor JD, Wilkie LI. Calcium in bile and calcium salts in gallstones. Clin Chim Acta 1977; 79: 119-27.

${ }^{23}$ Wolpers C. Auswahl der gallensteinträger zur litholyse. Leber Magen Darm 1976; 6: 43-6. 